\title{
Erodible time-dependent colon delivery systems with improved efficiency in delaying the onset of drug release
}

Maria Dorly Del Curto, Luca Palugan, Anastasia Foppoli, Lucia Zema, Andrea Gazzaniga*, Alessandra Maroni

Università degli Studi di Milano, Dipartimento di Scienze Farmaceutiche, Sezione di Tecnologia e Legislazione Farmaceutiche "M.E. Sangalli", Via G. Colombo 71, 20133 Milan, Italy.

*Corresponding Author: e-mail andrea.gazzaniga@unimi.it, phone +39 02503 24654, telefax +39

0250324658

\begin{abstract}
In order to prepare swellable/erodible time-dependent colon delivery systems with improved efficiency in delaying drug release, the application of an outer Eudragit ${ }^{\circledR} \mathrm{NE}$ film, which contained the superdisintegrant Explotab ${ }^{\circledR}$ V17 as a pore former, was attempted. Tablet cores were successively spray-coated with a hydroxypropyl methylcellulose (HPMC) solution and diluted Eudragit $^{\circledR}$ NE 30 D wherein fixed amounts of Explotab ${ }^{\circledR}$ V17 were present. The resulting two-layer systems yielded lag phases of extended duration as compared with formulations provided with the HPMC layer only. By raising the thickness of the outer film, longer lag times were generally observed whereas the effectiveness in deferring the drug liberation was reduced by increasing the pore former content, which, however, also resulted in a lower data variability. The films containing $20 \%$ of Explotab ${ }^{\circledR}$ V17 effectively and consistently prolonged the in vitro lag phase imparted by HPMC as a function of their thickness. Stored for 3 years under ambient conditions, a two-layer system with this outer film composition pointed out unmodified release patterns. The same system, proved to meet gastroresistance criteria when enteric-coated. The results obtained indicated that the proposed strategy would enable the preparation of erodible delivery systems with reduced size, possibly suitable as multiple-unit dosage forms.
\end{abstract}




\section{Keywords}

Controlled release/delivery, Oral drug delivery, Colonic drug delivery, Solid dosage form, Formulation, Pulsatile/delayed release, Swellable/erodible polymeric drug delivery systems, Filmcoating.

\section{Introduction}

In the field of oral delivery, not only dosage forms intended for prolonged release but also for a time-dependent or site-targeted drug liberation have drawn growing interest over the last two decades. ${ }^{1-3}$ Colon delivery, in particular, is a current focus of research because of its possible application in the treatment of large bowel pathologies, such as primarily inflammatory bowel disease (IBD), and to improve the oral bioavailability of peptides and proteins. ${ }^{4-6}$ Indeed, the colon is considered as a potentially favorable absorption site for these molecules especially due to the lower levels of proteases and greater responsiveness of the mucosa to permeation enhancers as compared with proximal intestinal regions. ${ }^{7-9}$ For colon delivery purposes, dosage forms for pulsatile release, intended to release the active ingredient following lag phases of programmable duration, can be exploited according to the time-based formulation approach, which is based on the relatively consistent small intestinal transit time (SITT). ${ }^{10-13}$ In this case, pulsatile delivery systems need to be enteric coated, so that unpredictable gastric residence time may be overcome, and provide a lag phase comparable to SITT.

Pulsatile delivery systems can be designed in the form of a drug-containing core and a hydrophilic swellable/erodible polymer coating that undergoes glassy-rubbery transition when in contact with aqueous fluids, thereby delaying the onset of drug liberation. ${ }^{14}$ In this case, rather thick functional layers are usually needed for in vivo delay phases consistent with colon targeting goals to be achieved. When a multiple-unit configuration of these systems is sought, the issue of a relatively high thickness for the polymer coatings can be particularly critical. Indeed, the resulting size may not comply with the dimensional requirements of such dosage forms, thus preventing their well- 
known benefits from being seized. ${ }^{15-17}$ Furthermore, the attainment of a prompt and quantitative release after the lag phase may be hindered by the bulky swollen polymer barrier.

Such problems have been encountered throughout the development of the Chronotopic $^{\mathrm{TM}}$ system, an erodible device characterized by a functional hydroxypropyl methylcellulose (HPMC) coating. When formulated in single units, this delivery platform proved to yield the desired in vitro and in vivo release performance and was recently demonstrated viable as an insulin carrier. ${ }^{18-22}$ However, in order to prepare such a system from small-sized cores, e.g. when shifting from tabletto minitablet-based formulations, a modification in its design was necessary. In particular, thin insoluble films provided with water permeability and marked flexibility characteristics were recently proposed for application onto its low-viscosity HPMC layer. ${ }^{23}$ Such films were intended to slow down the penetration of water into the functional HPMC coating thereby enhancing the inherent efficiency in delaying the drug liberation. However, they were expected not to exert a major influence on the swelling/erosion-dependent release mechanism of the system. For this purpose, a neutral polymethacrylate $\left(\right.$ Eudragit $\left.^{\circledR} \mathrm{NE} 30 \mathrm{D}\right)$ was selected as the film-forming agent in view of its favorable tensile properties and the mild process conditions involved. In addition, various superdisintegrants were evaluated for use as "non-conventional" pore formers able to impart the required permeability properties to the acrylic layer and ultimately aid its break-up. ${ }^{24}$ The preliminary screening, mainly performed with free films containing the superdisintegrants under investigation (Explotab ${ }^{\circledR}$ V17, Ac-Di-Sol ${ }^{\circledR}$, Kollidon $^{\circledR}$ CL and Kollidon ${ }^{\circledR}$ CL-M) at differing concentrations $\left(10 \%, 15 \%, 20 \%\right.$ on the dry polymer), indicated that Explotab ${ }^{\circledR}$ V17-based formulations would offer a potentially adequate balance between improvement of the permeability of Eudragit ${ }^{\circledR} \mathrm{NE}$ and maintenance of its advantageous flexibility properties. ${ }^{23}$ Therefore, such films were considered suitable candidates for application to the erodible delivery system previously described.

The aim of this work was thus to apply the identified Eudragit ${ }^{\circledR}$ NE/Explotab ${ }^{\circledR}$ V17 film formulations to HPMC-coated tableted cores and explore their impact on the overall release 
performance in order to assess the viability of the proposed approach in the design of erodible systems for time-dependent colon delivery with enhanced efficiency in delaying drug release and, consequently, reduced dimensions possibly consistent with those of multiple-unit dosage forms.

\section{Materials and Methods}

\section{Materials}

Colloidal silica (Syloid ${ }^{\circledR} 244$, Grace Davison, Columbia, Maryland, USA); copovidone (Kollidon ${ }^{\circledR}$ VA64, BASF, Ludwigshafen, Germany); hydroxypropyl methylcellulose (HPMC, Methocel ${ }^{\circledR}$ E50, Colorcon, Gallarate, Italy); magnesium stearate (Carlo Erba Reagenti, Milan, Italy); microcrystalline cellulose (Avicel ${ }^{\circledR}$ PH101, FMC Europe, Brussels, Belgium); paracetamol fine powder (Mallinckrodt, Hazelwood, Missouri, USA), paracetamol for direct compression (Compap ${ }^{\mathrm{TM}}$ Coarse L Mallinckrodt); poly(ethylacrylate, methylmethacrylate) 2:1, aqueous dispersion 30\% Eudragit $^{\circledR}$ NE 30 D, Evonik Röhm, Germany, distributed by Rofarma, Milan, Italy); poly(methacrylic acid, ethyl acrylate) 1:1, aqueous dispersion $30 \%$ (Eudragit $^{\circledR}$ L 30 D-55, Evonik Röhm); polyethylene glycol (PEG 400, ACEF, Fiorenzuola D'Arda, Italy); sodium starch glycolate $\left(\right.$ Explotab $^{\circledR}$ V17; Explotab ${ }^{\circledR}$, JRS Italia, Castenedolo, Italy).

\section{Methods}

A physical mixture consisting of $80.0 \%$ paracetamol for direct compression, $2.0 \%$ copovidone, $12.5 \%$ microcrystalline cellulose, $4.5 \%$ sodium starch glycolate, $0.5 \%$ colloidal silica and $0.5 \%$ magnesium stearate was compacted by a rotary machine (AM-8S, Officine Ronchi, Milan, Italy) equipped with concave punches of either $5 \mathrm{~mm}$ in diameter and $5 \mathrm{~mm}$ in curvature radius or $2.5 \mathrm{~mm}$ in diameter and $3 \mathrm{~mm}$ in curvature radius in the case of tablet and minitablet cores, respectively. The cores were checked for weight $(n=20)$, height by a digital micrometer (Absolute, Mitutoyo, Kawasaki, Japan; n=20), crushing strength (crushing tester TBH28, Erweka, Heusenstamm, Germany; $\mathrm{n}=10$ ), friability (friabilometer TA3R, Erweka; $6.5 \mathrm{~g}$ sample) and disintegration time 
(USP 36 disintegration apparatus DT3, Sotax, Basel, Switzerland; n=6). The measured values of tablet weight, height and crushing strength were $80.6 \pm 0.1 \mathrm{mg}, 3.98 \pm 0.02 \mathrm{~mm}$ and $6.9 \pm 0.5 \mathrm{kp}$, whereas such values were $10.2 \pm 0.6 \mathrm{mg}, 2.01 \pm 0.06 \mathrm{~mm}$ and $1.46 \pm 0.7 \mathrm{kp}$ in the case of minitablets. Friability and disintegration time were $<0.3 \%$ and $<1$ min with both tablet and minitablet cores. These units were subsequently coated by a rotary fluid bed (GPCG 1.1, Glatt, Binzen, Germany) with an $8.0 \% \mathrm{w} / \mathrm{v}$ HPMC $-0.8 \% \mathrm{w} / \mathrm{v}$ PEG 400 aqueous solution. The adopted operating conditions were: $750 \mathrm{~g}$ batch size, $55-60^{\circ} \mathrm{C}$ inlet air temperature, $40-45^{\circ} \mathrm{C}$ outlet air temperature, $26-28^{\circ} \mathrm{C}$ product temperature, $95 \mathrm{~m}^{3} / \mathrm{h}$ inlet air volume, $0.8 \mathrm{~mm}$ nozzle port size, 2.0 bar atomizing pressure and $2.5 \mathrm{~g} / \mathrm{min}$ spray rate. ${ }^{25} \mathrm{HPMC}$-coated cores along with uncoated ones were subsequently coated by a bottom-spray fluid bed with Eudragit ${ }^{\circledR}$ NE 30 D, as such or containing 10,15 or $20 \% \mathrm{w} / \mathrm{w}$ on the dry polymer of Explotab ${ }^{\circledR}$ V17. The superdisintegrant powder was allowed to swell in deionized water, and the resulting suspension was mixed with Eudragit ${ }^{\circledR} \mathrm{NE} 30 \mathrm{D}$ under gentle stirring. The following operating conditions were set up: $200 \mathrm{~g}$ batch size, $35-37^{\circ} \mathrm{C}$ inlet air temperature, 27 $29^{\circ} \mathrm{C}$ outlet air temperature, $26-28^{\circ} \mathrm{C}$ product temperature, $65-70 \mathrm{~m}^{3} / \mathrm{h}$ inlet air volume, $1.2 \mathrm{~mm}$ nozzle port size, 2.0 bar atomizing pressure and $2 \mathrm{~g} / \mathrm{min}$ spray rate. In order to check the progression of the coating process, weight gain $(n=20)$ was calculated by subtracting the mean weight of uncoated cores from that of coated ones. Curing was then carried out at $40^{\circ} \mathrm{C}$ for $24 \mathrm{~h}$ in an oven.

Coat thickness was measured by scanning electron microscope (SEM; Sigma, Zeiss, Oberkochen, Germany) analysis. Digital photomicrographs of cross-sectioned two-layer systems were acquired after gold sputtering. The obtained data were the average of 20 measurements performed in differing areas of the coating of several units. In the case of nominal $10 \mu \mathrm{m}, 20 \mu \mathrm{m}$ and $30 \mu \mathrm{m}$ thicknesses of the outer Eudragit $^{\circledR} \mathrm{NE} /$ Explotab $^{\circledR} \mathrm{V} 17 \mathrm{film}$, the measured values were $9.3 \pm 2.1 \mu \mathrm{m}$, 22.0 $\pm 3.5 \mu \mathrm{m}$ and $31.3 \pm 4.1 \mu \mathrm{m}$, whereas those relevant to the inner HPMC coating were $249.2 \pm 20.6$ $\mu \mathrm{m}$ and $148.5 \pm 15.6 \mu \mathrm{m}$. 
An outline of all formulations that were manufactured and evaluated is reported in Table 1; only the one having a minitablet core, $250 \mu \mathrm{m}$ HPMC coating and $20 \mu \mathrm{m}$ Eudragit $^{\circledR}$ NE/Explotab ${ }^{\circledR}$ V17 film containing 20\% of Explotab ${ }^{\circledR}$ V17 (mHENex20) was further coated with diluted Eudragit ${ }^{\circledR}$ L 30 D55 (15.9\% of dry polymer in the coating suspension) by bottom-spray fluid bed up to a nominal enteric film thickness of $100 \mu \mathrm{m}$, corresponding to a $10 \mathrm{mg} / \mathrm{cm}^{2}$ amount of polymer. The coating conditions were: $200 \mathrm{~g}$ batch size, $30-32^{\circ} \mathrm{C}$ inlet air temperature, $23-25^{\circ} \mathrm{C}$ outlet air temperature, $22-24^{\circ} \mathrm{C}$ product temperature, $65-70 \mathrm{~m}^{3} / \mathrm{h}$ inlet air volume, $1.2 \mathrm{~mm}$ nozzle port size, $2.0 \mathrm{bar}$ atomizing pressure and $3 \mathrm{~g} / \mathrm{min}$ spray rate. A final curing step was then performed at $40^{\circ} \mathrm{C}$ for $2 \mathrm{~h}$ in an oven.

In vitro release tests $(\mathrm{n}=3)$ were carried out by means of a modified disintegration testing method (800 $\mathrm{ml}$ of fluid, $37 \pm 1^{\circ} \mathrm{C}$ ) in order to overcome adhesion of the hydrated HPMC coating to the vessels of a paddle dissolution apparatus, as described previously. ${ }^{26}$ All formulations were tested in phosphate buffer $\mathrm{pH}$ 6.8. Only the enteric-coated system was tested in $\mathrm{HCl} 0.1 \mathrm{~N}$ for $2 \mathrm{~h}$ and, subsequently, in phosphate buffer $\mathrm{pH}$ 6.8. Fluid samples were withdrawn at successive time points and assayed by spectrophotometer (Lambda 25, Perkin Elmer, Monza, Italy) at $\lambda=248 \mathrm{~nm}$ after verifying agreement of results between the relevant method and a HPLC one. For this purpose, the approach reported in USP 37 General Chapter "Analytical Data-Interpretation and Treatment" ("Comparison of analytical methods", p. 519) was followed. ${ }^{27}$ Samples were collected at 4 selected time points $(0.6-70.0 \mu \mathrm{g} / \mathrm{ml}$ concentration range) during the release test of cores and coated systems having maximum coat thicknesses and Explotab ${ }^{\circledR}$ V17 concentrations. Each sample was analyzed $(n=6)$ by both UV and reverse phase-HPLC (column: $\mathrm{C}_{18}$ at $40^{\circ} \mathrm{C}$, mobile phase: deionized water for HPLC/acetonitrile/perchloric acid 3000:1000:3 v/v at $\mathrm{pH}=2.4$, flow rate: $1.2 \mathrm{ml} / \mathrm{min}$, detection: UV at $248 \mathrm{~nm}$, injection volume: $40 \mu \mathrm{l}$ ) using freshly prepared standard solutions as a reference. The $95 \%$ confidence intervals for the differences in the sample means (UV minus HPLC) fell in the $\pm 2 \%$ range with respect to the HPLC mean, which was considered acceptable within the scientific context concerned. ${ }^{27,28}$ 
Release testing of the two-layer minitablet-based system with $20 \%$ of Explotab ${ }^{\circledR}$ V17 in the outer film, stored in sealed plastic bags under ambient conditions $\left(25 \pm 1^{\circ} \mathrm{C} / 55 \pm 5 \% \mathrm{RH}\right)$ for 3 years, was repeated at programmed time points. In vitro lag time was expressed as the time to $10 \%$ drug release $\left(\mathrm{t}_{10 \%}\right)$ in phosphate buffer $\mathrm{pH}$ 6.8. $\mathrm{t}_{10 \%}$ values were calculated by linear interpolation of data immediately before and after $10 \%$ drug release. In order to statistically compare $t_{10 \%}$ means, unpaired two-group two-tail t-student test was performed (Excel 2007, Microsoft, Redmond, Washington, USA) accounting for heteroscedasticity. The differences were considered significant with $\mathrm{p}<0.05$.

The morphological changes of two-layer minitablet-based systems occurring upon the relevant exposure to aqueous media were evaluated by placing each sample $(n=3)$, fixed on a pin, in a beaker containing $50 \mathrm{ml}$ of phosphate buffer $\mathrm{pH} 6.8$ immersed in an oscillating bath (SW22, Julabo Italia, Milan, Italy; $\left.37 \pm 1^{\circ} \mathrm{C}, 100 \mathrm{rpm}\right)$. At predetermined time intervals, measurements of the sample diameter were performed on digital photographs (digital photocamera Nikon D70, Nital, Torino, Italy) with the aid of an image-editing software (Photoshop 7.0, Adobe, San Jose, California, USA). The $\%$ variation in diameter was calculated according to the following equation:

$\%$ variation in diameter $=\frac{\left(d_{t}-d_{0}\right)}{d_{0}} \cdot 100$

where $d_{0}$ and $d_{t}$ are the starting diameter and the diameter measured at each time point, respectively. ${ }^{29}$

\section{Results and Discussion}

According to the results from a previous screening study, Eudragit ${ }^{\circledR} \mathrm{NE}$ formulations containing Explotab $^{\circledR}$ V17 were selected for more in-depth evaluation in terms of impact on the in vitro release performance of HPMC-coated pulsatile delivery systems. ${ }^{23}$ Eudragit $^{\circledR}$ NE/Explotab ${ }^{\circledR}$ V 17 films, at $10 \%, 15 \%$ or $20 \%$ of superdisintegrant on the dry polymer, were thus applied to tablets $(5 \mathrm{~mm})$ and 
minitablets $(2.5 \mathrm{~mm})$, chosen as cores of reduced size, provided with a swellable/erodible HPMC coating of $250 \mu \mathrm{m}$.

The aqueous film-coating process was feasible with all tested compositions, requiring only minor adjustments of the operating conditions when shifting from tablet to minitablet cores. Coated systems with nominal outer film thicknesses of $10 \mu \mathrm{m}, 20 \mu \mathrm{m}$ and $30 \mu \mathrm{m}$ were obtained within 60 min of processing. Such films were continuous and, possibly due to the incorporated superdisintegrant particles, presented a rough surface (Figure 1).

When subjected to in vitro release testing, tablet-based devices provided with Eudragit ${ }^{\circledR} \mathrm{NE}$ films having $10 \%$ of Explotab ${ }^{\circledR} \mathrm{V} 17$ (tHENex 10) and thickness of $10 \mu \mathrm{m}$ gave rise to a typical pulsatile delivery profile with a significantly more extended $(\mathrm{p}<0.05)$ lag time as compared with starting HPMC-coated units (tH) (Figure 2). In particular, the mean $t_{10 \%}$, i.e. the time to $10 \%$ release, was more than tripled by the presence of the external coat. However, the individual data were affected by a relatively high variability, which appeared worsened in the case of $20 \mu \mathrm{m}$-thick films. Indeed, one of the three specimens with this nominal outer film thickness did not start releasing within the whole duration of the test $(10 \mathrm{~h})$, and only one showed a fast and quantitative liberation of the active ingredient after a lag phase of approximately $9 \mathrm{~h}$. Such a delay phase was by far longer than those in the 60-120 min range formerly shown by analogous systems, tested under the same conditions, which were demonstrated to yield in vivo lag times potentially suitable for timecontrolled colon targeting. ${ }^{25}$ These findings may indicate that, at the coating thickness of $20 \mu \mathrm{m}$, a $10 \%$ concentration of the pore former would not be sufficient to ensure a homogeneous distribution thereof in the film thus resulting in a slow and erratic hindrance to the hydration of the underlying HPMC layer. Accordingly, the in vitro behavior of tHENex10 with a $30 \mu \mathrm{m}$ nominal thickness of the outer film was not considered worthy of evaluation.

The systems with $15 \%$ and $20 \%$ of Explotab $^{\circledR}$ V17 in the Eudragit ${ }^{\circledR}$ NE coat, i.e. tHENex 15 and tHENex20, respectively, still yielded significantly longer $(\mathrm{p}<0.05)$ lag times as compared with onelayer HPMC-coated units, although the relevant duration was reduced with respect to that of 
tHENex 10 except for tHENex15 with $10 \mu$ m-thick film (Figures 3 and 4). Notably, fairly

reproducible lag times were observed prior to a fast liberation of the tracer drug in the case of outer films of $10 \mu \mathrm{m}$. On the other hand, with thicker coats, namely 20 and $30 \mu \mathrm{m}$, the onset of release was poorly reliable and, due to the high variability encountered, the performance could not be distinguished as a function of the coating level.

As expected, the percentage of Explotab ${ }^{\circledR}$ V17 and the thickness of the external film had an opposite influence on the release pattern (Table 2). The superdisintegrant content would indeed affect the permeability of the polymeric barrier, reasonably because of the hydrophilicity conferred and the gaps formed following hydration and possible leaching out of the pore former into the bulk medium. This would lead to an earlier and faster swelling of HPMC and, in turn, break-up of the system. In contrast, by increasing the thickness of the outermost coat, the relevant toughness would also be enhanced. Therefore, when thicker films are applied, HPMC would not only undergo a slower hydration because of hindered penetration of water but also need to swell to a greater extent before the disruption of the overlaid coating occurs, thus being reflected in longer lag phases and, possibly, in an erratic onset of release.

When considering two-layer systems based on minitablet cores, only the film-forming formulations at $15 \%$ and $20 \%$ of superdisintegrant (mHENex 15 and mHENex 20 , respectively) were considered (Figures 5 and 6). The unreliable release data obtained from tHENex10 systems were indeed ascribed to an insufficient concentration of pore former.

Minitablets with a $250 \mu \mathrm{m}$ HPMC coating $(\mathrm{mH})$ provided shorter delay phases than the previously investigated tablet-based systems $(\mathrm{tH})$ reasonably because of the overall smaller amount of polymer applied (7.0 mg vs. $21.6 \mathrm{mg}$ ). Moreover, although able to prolong the duration of the delay period as compared with the starting HPMC-coated minitablets, the film formulations containing $15 \%$ and $20 \%$ of Explotab ${ }^{\circledR}$ V17 were generally demonstrated less effective than in the case of two-layer systems based on $5 \mathrm{~mm}$ tablets, and a more pronounced slow drug liberation phase, during which $\sim 15 \%$ of active ingredient leached out via a diffusion mechanism, was evident prior to the release 
pulse. This may be ascribed to the relatively larger surface area available for diffusion exposed by smaller units, and, in addition, the wider surface might lead to a broader spread of the disintegration pressure exerted by the core upon water inflow, which would less effectively promote a prompt break-up of the system at the end of the lag phase. As previously observed with the systems prepared from $5 \mathrm{~mm}$ cores, the release profiles of mHENex15 and mHENex20 were also strongly affected by the coating level and superdisintegrant content of the outer film. By raising the former, longer lag times were achieved from both formulations. However, the extent of variability markedly increased with the film thickness in the case of mHENex15. While the films containing Explotab ${ }^{\circledR}$ V17 at $20 \%$, because of the higher hydrophilicity, turned out to extend the duration of the lag phase to a lesser extent than mHENex 15, the relevant data variability was reduced thus pointing out a more reliable performance and, possibly, a minor impact on the HPMC swelling and erosion phenomena. Interestingly, the average $\mathrm{t}_{10 \%}$ of mHENex20 with outer films of 20 and $30 \mu \mathrm{m}$, respectively, was more than three- and four-fold as compared with the $\mathrm{mH}$ reference formulation (Table 3).

In order to investigate the role played by the applied films, the changes undergone by mHENex 15 and mHENex20 systems with $30 \mu \mathrm{m}$-thick Eudragit ${ }^{\circledR} \mathrm{NE} /$ Explotab $^{\circledR}$ V17 coats while immersed in phosphate buffer $\mathrm{pH} 6.8$ were monitored $v$ s. the reference one-layer system $(\mathrm{mH})$ (Figures 7 and 8). The latter showed an initial increase in volume due to the swelling of HPMC, directly exposed to the medium (Figure 7a). Afterwards, a progressive reduction in size, brought about by the erosion and dissolution of the hydrated polymer, was observed until complete disintegration at $90 \mathrm{~min}$. As compared with $\mathrm{mH}, \mathrm{mHENex} 15$ was subject to a slower expansion that also continued after the external film started to break up (Figure 7b). In this respect, it was hypothesized that the poor permeability of such a film would not enable a rapid hydration of the underlying HPMC layer, and the consequently slow swelling process would not result in a fast and homogeneous rupture of the film itself, which rather underwent the gradual formation of breaches and fissures. 
In the case of mHENex20 (Figure 7c), a swelling phase was initially noticed, much faster than with mHENex 15 though slower than with $\mathrm{mH}$. This was ascribed to a relatively rapid permeation of water through the external film, which allowed extensive hydration of HPMC while maintaining its integrity and progressively adapting to the expansion of the core unit. Subsequently, after failure of such a film and direct exposure of HPMC to the fluid, the hydrophilic polymer layer underwent a gradual erosion that led to a decrease in the system size.

Accordingly, the $\%$ variation in diameter $v s$. time curves obtained pointed out marked differences between the two-layer formulations under investigation (Figure 8). The pattern of mHENex20 was less differentiated from that of systems coated with HPMC only, with a slower and more persistent swelling that would account for the extended delays observed in the previous drug release profiles. Interestingly, mHENex20 had already reached its maximum expansion by the time of break-up of the outer film, which was thereby demonstrated not to limit the extent of swelling of the HPMC layer. This was not surprising in view of the tensile properties displayed by isolated films with the same composition. ${ }^{23}$ Indeed, the wet free film underwent a more than four-fold elongation at break. Soon after the outer film disruption, i.e. when the polymer erosion/dissolution was no longer hampered, the diameter of mHENex20 started to decrease. By contrast, mHENex 15 gained a \% increase in volume by far lower than that exhibited by the other investigated systems over the same timeframe and kept expanding after rupture of the relevant film. As wet isolated films with the same composition were able to stretch up to approximately 5 times with respect to their original length, and no limitation to the extent of swelling was highlighted in the case of mHENex20 despite the greater amount of Explotab ${ }^{\circledR}$ V17, which could have been expected to more deeply impact on the inherent flexibility properties of the polymethacrylate, the possibility that the HPMC expansion would mechanically be restrained in mHENex15 could be ruled out. The applied film was thus assumed to hinder a fast and extensive water uptake in view of its low permeability barrier characteristics. 
Moreover, by relating the observed morphological changes to the profile of drug concentration in the immersion fluid, the onset of drug release from mHENex 20 was assessed to coincide with the beginning of the core disintegration (data not shown). Because this occurred largely after breakage of the outer film, it was hypothesized that the latter would merely act as a temporary hindrance to water uptake and erosion phenomena rather than as a rupturable coating chiefly responsible for controlling the onset of release.

The film containing $20 \%$ of Explotab ${ }^{\circledR}$ V17 was thus demonstrated to provide the desired prolongation of lag time without any major influence on the release mode, i.e. a fast release phase after the delay period was preserved. In order to better elucidate the role of such a film formulation in the control of drug liberation, systems without the intermediate hydrophilic coat were prepared and evaluated (Figure 9). Minitablets provided with a Eudragit ${ }^{\circledR}$ NE/Explotab ${ }^{\circledR}$ V17 (20\%) film (mENex20) of $20 \mu \mathrm{m}$ showed a reproducible latency on the order of minutes, and a somewhat sigmoidal release profile. Although extended by the film of $30 \mu \mathrm{m}$, the lag period was much shorter than that exhibited by the corresponding two-layer system and still far from suitability for colon delivery purposes. From these results it was inferred that the Eudragit ${ }^{\circledR}$ NE/Explotab ${ }^{\circledR}$ V17 film formulation as such would provide a minor contribution to the overall duration of the lag phase. It was therefore evident that the HPMC layer would also be needed for a sufficient delay in the onset of drug liberation to be achieved and, probably, for the outer film break-up to be promoted, thereby avoiding a major impact on the rate of release. Importantly, because the lag time observed with twolayer units (mHENex20) was longer than the sum of those yielded by each single layer, a synergistic interplay should be assumed to operate between the HPMC and Eudragit ${ }^{\circledR}$ NE/Explotab ${ }^{\circledR}$ V17 coats.

The influence of the HPMC coating level was subsequently explored with the aim of further reducing, if possible, the overall dimensions of the final dosage forms whilst preserving a consistent pulsatile release behavior. For this purpose, minitablet-based systems provided with a thinner HPMC coat $(150 \mu \mathrm{m})$ along with a $10 \mu \mathrm{m}, 20 \mu \mathrm{m}$ or $30 \mu \mathrm{m}$ Eudragit ${ }^{\circledR} \mathrm{NE}$ film with Explotab ${ }^{\circledR}$ V17 
at $20 \%(\mathrm{mH} 150 \mathrm{ENex} 20)$ were prepared, and their performance was compared with that of the corresponding systems having a $250 \mu \mathrm{m}$ thick HPMC layer (Figure 10). In these cases, the duration of the lag period was shorter as expected in view of a lower HPMC coating level. Moreover, although such two-layer formulations proved capable of prolonging the lag time lapse imparted by the sole HPMC coating, the variability in the onset of the release pulse and the tendency to a diffusive drug liberation were amplified when increasing the thickness of the outer Eudragit ${ }^{\circledR}$ $\mathrm{NE} /$ Explotab $^{\circledR} \mathrm{V} 17$ to $30 \mu \mathrm{m}$. In this respect, it is likely that, at a thickness of $150 \mu \mathrm{m}$, the expansion of the HPMC coating would be lower thus turning out less effective in aiding rupturing of the overlaid film, as highlighted during the release test. Therefore, not only the permeability and flexibility characteristics of the external coat but also the extent of swelling of the hydrophilic layer could be critical for the achievement of the desired release profile.

Finally, the release performance of the mHENex20 system with an outer film of $20 \mu \mathrm{m}$, stored under ambient conditions, was evaluated over a three-year time lapse (Figure 11). $t_{10 \%}$ data were not significantly changed throughout the whole period, which indicated that the behavior of the overall formulation would not be altered as a consequence of storage, and the impact of any possible change in the dissolution characteristics of paracetamol would not be highlighted. ${ }^{30}$

The same system was subjected to enteric coating in view of the final goal of the work, i.e. the design and evaluation of an oral delivery system for time-dependent colonic release. Such a system was able to withstand exposure to a $0.1 \mathrm{~N} \mathrm{HCl}$ solution for $2 \mathrm{~h}$ and, when immersed in phosphate buffer $\mathrm{pH} 6.8$, the release pattern provided was comparable to that shown by its non-gastroresistant counterpart, thus confirming the formation of a continuous Eudragit ${ }^{\circledR}$ L film and lack of alteration of the underlying functional layers possibly brought about by enteric coating (Figure 12).

\section{Conclusions}

Previously identified Eudragit ${ }^{\circledR}$ NE/Explotab ${ }^{\circledR}$ V17 film-forming formulations containing differing amounts of the superdisintegrant (10-20\% on polymer) were applied to HPMC-coated tablet and 
minitablet cores up to increasing levels. The outer films were generally demonstrated to extend the lag phase imparted by HPMC as a function of their thickness and superdisintegrant content. Particularly, the formulation with $20 \%$ of Explotab ${ }^{\circledR}$ V17 proved able to consistently enhance the efficiency of the hydrophilic layer in delaying the onset of drug liberation without any major impact on the relevant rate. Indeed, such a film was assumed to only slightly affect the swelling pattern of the underlying HPMC layer and not to limit its expansion upon hydration. The swellable/erodible coating was confirmed to play a crucial role in defining the release pattern, and a sufficient thickness thereof was needed in order to preserve the pulsatile release mode pursued. However, the performance obtained was proved to result from a synergistic interplay between the two overlaid layers.

The release behavior of a two-layer delivery system consisting in minitablet cores provided with a $250 \mu \mathrm{m}$ HPMC coat and a $20 \mu \mathrm{m}$ Eudragit $^{\circledR}$ NE film at $20 \%$ of Explotab ${ }^{\circledR}$ V17 was demonstrated consistent over a period of 3 years, during which the samples were stored under ambient conditions. Finally, the application of a Eudragit ${ }^{\circledR}$ L gastroresistant coating prevented not only the drug liberation but also activation of the time-programmed lag phase while this formulation was immersed in the acidic fluid, without hindering the pulsatile release behaviour expected in the subsequent buffer medium.

Based on the overall results, the application of Eudragit ${ }^{\circledR} \mathrm{NE} /$ Explotab $^{\circledR}$ V17 films with appropriate thickness and composition was proved to be a viable formulation strategy to enhance the efficiency of the previously proposed swellable/erodible time-dependent colon delivery system in delaying drug release, thus allowing the relevant size to be reduced and the versatility as well as feasibility of the release platform to be improved.

\section{References}


1. Bussemer T, Otto I, Bodmeier R 2001. Pulsatile drug-delivery systems. Crit Rev Ther Drug Carrier Syst 18:433-458.

2. Grassi M., Zema L, Sangalli ME, Maroni A, Giordano F, Gazzaniga A 2004. Modeling of Drug Release from Partially Coated Matrices Made of a High Viscosity HPMC. Int J Pharm 276:107114.

3. Pinto JF 2010. Site-specific drug delivery systems within the gastro-intestinal tract: From the mouth to the colon. Int J Pharm 395:44-52.

4. Gazzaniga A, Giordano F, Sangalli ME, Zema L 1994. Oral colon-specific drug delivery: Design strategies. STP Pharma Prat 4:339-343.

5. Gazzaniga A, Maroni A, Sangalli ME, Zema L 2006. Time-controlled oral delivery systems for colon targeting. Expert Opin Drug Delivery 3:583-597.

6. Maroni A, Del Curto MD, Zema L, Foppoli A, Gazzaniga A 2014. Film coatings for oral colon delivery. Int J Pharm 457:372-394.

7. Bourgeois S, Harvey R, Fattal E 2005. Polymer colon drug delivery systems and their application to peptides, proteins, and nucleic acids. Am J Drug Delivery 3:171-204.

8. Haupt S, Rubinstein A 2002. The colon as a possible target for orally administered peptide and protein drugs. Crit Rev Ther Drug Carrier Syst 19:499-551. 
9. Maroni A, Zema L, Del Curto MD, Foppoli A, Gazzaniga A 2012. Oral colon delivery of insulin with the aid of functional adjuvants. Adv Drug Delivery Rev 64:540-556.

10. Conte U, Colombo P, La Manna A, Gazzaniga A, Sangalli ME, Giunchedi P 1989. A new Ibuprofen pulsed release oral dosage form. Drug Dev Ind Pharm 15:2583-2596.

11. Maroni A, Zema L, Loreti, G, Palugan, L, Gazzaniga, A 2014. Film coatings for oral pulsatile release. Int. J. Pharm. 457, 362-371.

12. Maroni A, Zema L, Del Curto MD, Loreti G, Gazzaniga A 2010. Oral pulsatile delivery: Rationale and chronopharmaceutical formulations. Int J Pharm 398:1-8.

13. Maroni A, Zema L, Cerea M, Sangalli, ME 2005. Oral pulsatile drug delivery systems. Expert Opin Drug Delivery 2:855-871.

14. Gazzaniga A, Palugan L, Foppoli A, Sangalli ME 2008. Oral pulsatile delivery systems based on swellable hydrophilic polymers. Eur J Pharm Biopharm 68:11-18.

15. Bianchini R, Bruni G, Gazzaniga A, Vecchio C 1993. d-Indobufen extended-release pellets prepared by coating with aqueous polymer dispersions. Drug Dev Ind Pharm 19:2021-2041.

16. Bianchini R, Bruni G, Gazzaniga A, Vecchio C 1992. Influence of extrusion-spheronization processing on the physical properties of d-Indobufen pellets containing $\mathrm{pH}$ adjusters. Drug Dev Ind Pharm 18:1485-1503.

17. Bodmeier R 1997. Tableting of coated pellets. Eur J Pharm Biopharm 43:1-8. 
18. Sangalli ME, Maroni A, Zema L, Busetti C, Giordano F, Gazzaniga A 2001. In vitro and in vivo evaluation of an oral system for time and/or site-specific drug delivery. J Controlled Release 73:103-110.

19. Zema L, Maroni A, Foppoli A, Palugan L, Sangalli ME, Gazzaniga A 2007. Different HPMC viscosity grades as coating agents for an oral time and/or site-controlled delivery system: An investigation into the mechanisms governing drug release. J Pharm Sci 96:1527-1536.

20. Maroni A, Del Curto MD, Serratoni M, Zema L, Foppoli A, Gazzaniga A, Sangalli ME 2009. Feasibility, stability and release performance of a time-dependent insulin delivery system intended for oral colon release. Eur J Pharm Biopharm 72:246-251.

21. Del Curto MD, Maroni A, Foppoli A, Zema L, Gazzaniga A, Sangalli ME 2009. Preparation and evaluation of an oral delivery system for time-dependent colon release of insulin and selected protease inhibitor and absorption enhancer compounds. J Pharm Sci 98:4661-4669.

22. Del Curto MD, Maroni A, Palugan L, Zema L, Gazzaniga A, Sangalli ME 2011. Oral delivery system for two-pulse colonic release of protein drugs and protease inhibitor/absorption enhancer compounds. J Pharm Sci 100:3251-3259.

23. Maroni A, Del Curto MD, Cerea M, Zema L, Foppoli A, Gazzaniga A 2013. Polymeric coatings for a multiple-unit pulsatile delivery system: Preliminary study on free and applied films. Int J Pharm 440:256-263. 
24. Schellekens RCA, Stellaard F, Mitrovic D, Stuurman FE, Kosterink JGW, Frijlink HW 2008. Pulsatile drug delivery to ileo-colonic segments by structured incorporation of disintegrants in $\mathrm{pH}$ responsive polymer coatings. J Controlled Release 132:91-98.

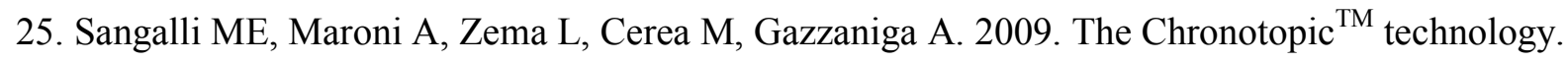
In Youan, B-BC, editor. Chronopharmaceutics, Hoboken: John Wiley\&Sons p 146-163.

26. Gazzaniga A, Busetti C, Moro L, Sangalli ME, Giordano F 1995. Time-dependent oral delivery systems for colon targeting. STP Pharma Sci 5:83-88.

27. Chambers D, Kelly G, Limentani G, Lister A, Lung KR, Warner E 2005. Analytical Method Equivalency. An Acceptable Analytical Practice. Pharmaceutical Technology 29:64-80.

28. Wells M and Dantus M 2004. Validation of Chromatographic Methods. In Cazes J Editor, Ewing's Analytical Instrumentation Handbook, $3^{\text {rd }}$ edition, Boca Raton: CRC Press p 1028.

29. Lecomte F, Siepmann J, Walther M, MacRae RJ, Bodmeier R 2005. pH-sensitive polymer blends used as coating materials to control drug release from spherical beads: Elucidation of the underlying mass transport mechanisms. Pharm Res 22:1129-1141.

30. Giordano F, Rossi A, Bettini R, Savioli A, Gazzaniga A, Novák Cs 2002. Thermal behavior of paracetamol polymeric excipients mixtures. J Therm Anal Calorim 68:575-590. 
Table 1. Outline of a two-layer system and summary of the formulations prepared

\begin{tabular}{|c|c|}
\hline \multicolumn{2}{|c|}{ 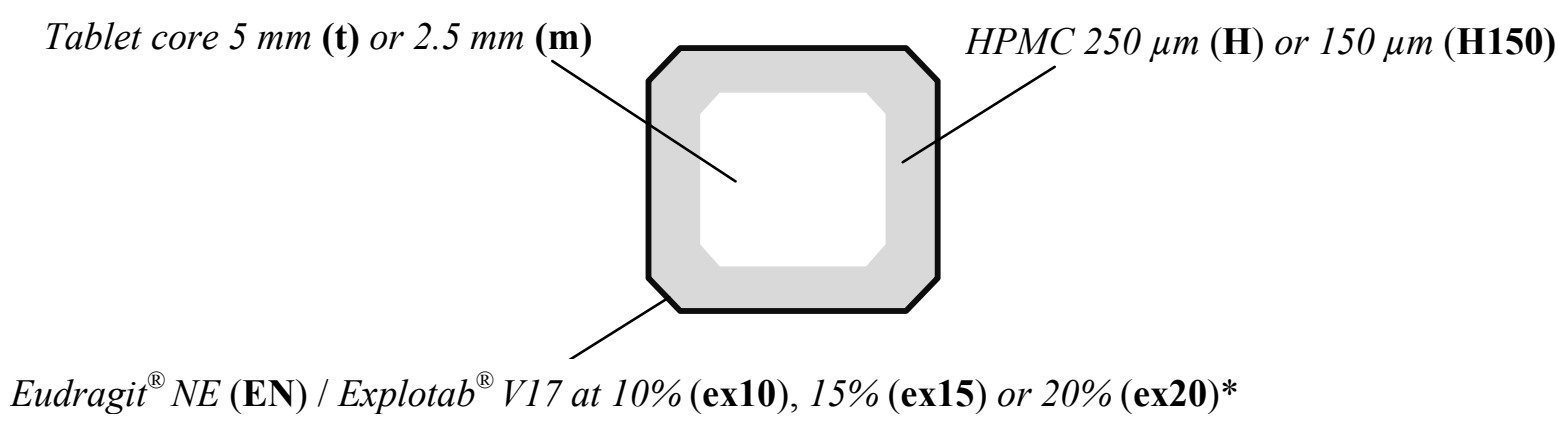 } \\
\hline Formulation code & Composition \\
\hline $\mathbf{T}$ & Tablet core $(5 \mathrm{~mm})$ \\
\hline tH & Tablet core $(5 \mathrm{~mm})+H P M C(250 \mu \mathrm{m})$ \\
\hline tHENex10 & Tablet core $(5 \mathrm{~mm})+$ HPMC $(250 \mu \mathrm{m})+$ Eudragit $^{\circledR} \mathrm{NE} /$ Explotab $^{\circledR}$ V17 10\% \\
\hline tHENex15 & Tablet core $(5 \mathrm{~mm})+$ HPMC $(250 \mu \mathrm{m})+$ Eudragit $^{\circledR} \mathrm{NE} /$ Explotab $^{\circledR}$ V17 15\% \\
\hline tHENex20 & Tablet core $(5 \mathrm{~mm})+$ HPMC $(250 \mu \mathrm{m})+$ Eudragit $^{\circledR} \mathrm{NE} /$ Explotab $^{\circledR}$ V17 20\% \\
\hline M & Minitablet core $(2.5 \mathrm{~mm})$ \\
\hline $\mathbf{m H}$ & Minitablet core $(2.5 \mathrm{~mm})+H P M C(250 \mu \mathrm{m})$ \\
\hline mHENex15 & Minitablet core $(2.5 \mathrm{~mm})+$ HPMC $(250 \mu \mathrm{m})+$ Eudragit $^{\circledR} \mathrm{NE} /$ Explotab $^{\circledR}$ V17 15\% \\
\hline mHENex $20 * *$ & Minitablet core $(2.5 \mathrm{~mm})+$ HPMC $(250 \mu \mathrm{m})+$ Eudragit $^{\circledR} \mathrm{NE} /$ Explotab $^{\circledR} \mathrm{V} 1720 \%$ \\
\hline mENex20 & Minitablet core $(2.5 \mathrm{~mm})+$ Eudragit $^{\circledR}$ NE/Explotab ${ }^{\circledR}$ V17 20\% \\
\hline mH150ENex20 & Minitablet core $(2.5 \mathrm{~mm})+$ HPMC $(150 \mu \mathrm{m})+$ Eudragit $^{\circledR} \mathrm{NE} /$ Explotab $^{\circledR}$ V17 20\% \\
\hline
\end{tabular}

*\% of Explotab $^{\circledR}$ V17 on dry Eudragit $\left.{ }^{(}\right) \mathrm{NE}$

** This formulation was enteric coated with Eudragit ${ }^{\circledR}$ L 30 D-55 
Table 2. $\mathrm{t}_{10 \%}$ of tablet-based formulations

\begin{tabular}{|l|c|}
\hline Formulations & $\boldsymbol{t}_{10 \%} \pm$ S.D.(min) \\
\hline tH & $33.3 \pm 3.4$ \\
\hline tHENex10 $10 \mu \mathrm{m}$ & $110.8 \pm 27.3$ \\
\hline tHENex10 $20 \mu \mathrm{m}$ & $530.4^{\circ}$ \\
\hline tHENex10 $30 \mu \mathrm{m}$ & - \\
\hline tHENex15 $10 \mu \mathrm{m}$ & $137.1 \pm 11.1$ \\
\hline tHENex15 $20 \mu \mathrm{m}$ & $349.4 \pm 69.4$ \\
\hline tHENex15 $30 \mu \mathrm{m}$ & $438.9 \pm 97.9$ \\
\hline tHENex20 $10 \mu \mathrm{m}$ & $74.5 \pm 8.2$ \\
\hline tHENex20 $20 \mu \mathrm{m}$ & $212.9 \pm 44.0$ \\
\hline tHENex20 $30 \mu \mathrm{m}$ & $260.5 \pm 47.9$ \\
\hline
\end{tabular}

${ }^{\circ}$ Mean of two replicates. 
Table 3. $t_{10 \%}$ of minitablet-based formulations

\begin{tabular}{|l|c|}
\hline Formulations & $\boldsymbol{t}_{10 \%} \pm$ S.D.(min) \\
\hline $\mathrm{mH}$ & $22.3 \pm 1.5$ \\
\hline mHENex15 $10 \mu \mathrm{m}$ & $75.2 \pm 5.2$ \\
\hline mHENex15 $20 \mu \mathrm{m}$ & $204.0 \pm 69.3$ \\
\hline mHENex15 $30 \mu \mathrm{m}$ & $214.3 \pm 62.7$ \\
\hline mHENex20 $10 \mu \mathrm{m}$ & $51.1 \pm 0.9$ \\
\hline mHENex20 $20 \mu \mathrm{m}$ & $69.3 \pm 3.6$ \\
\hline mHENex20 $30 \mu \mathrm{m}$ & $126.8 \pm 10.4$ \\
\hline mH150 & $16.7 \pm 2.7$ \\
\hline mH150ENex20 $10 \mu \mathrm{m}$ & $31.7 \pm 4.8$ \\
\hline mH150ENex20 $20 \mu \mathrm{m}$ & $56.5 \pm 4.6$ \\
\hline mH150ENex20 $30 \mu \mathrm{m}$ & $100.3 \pm 15.0$ \\
\hline
\end{tabular}



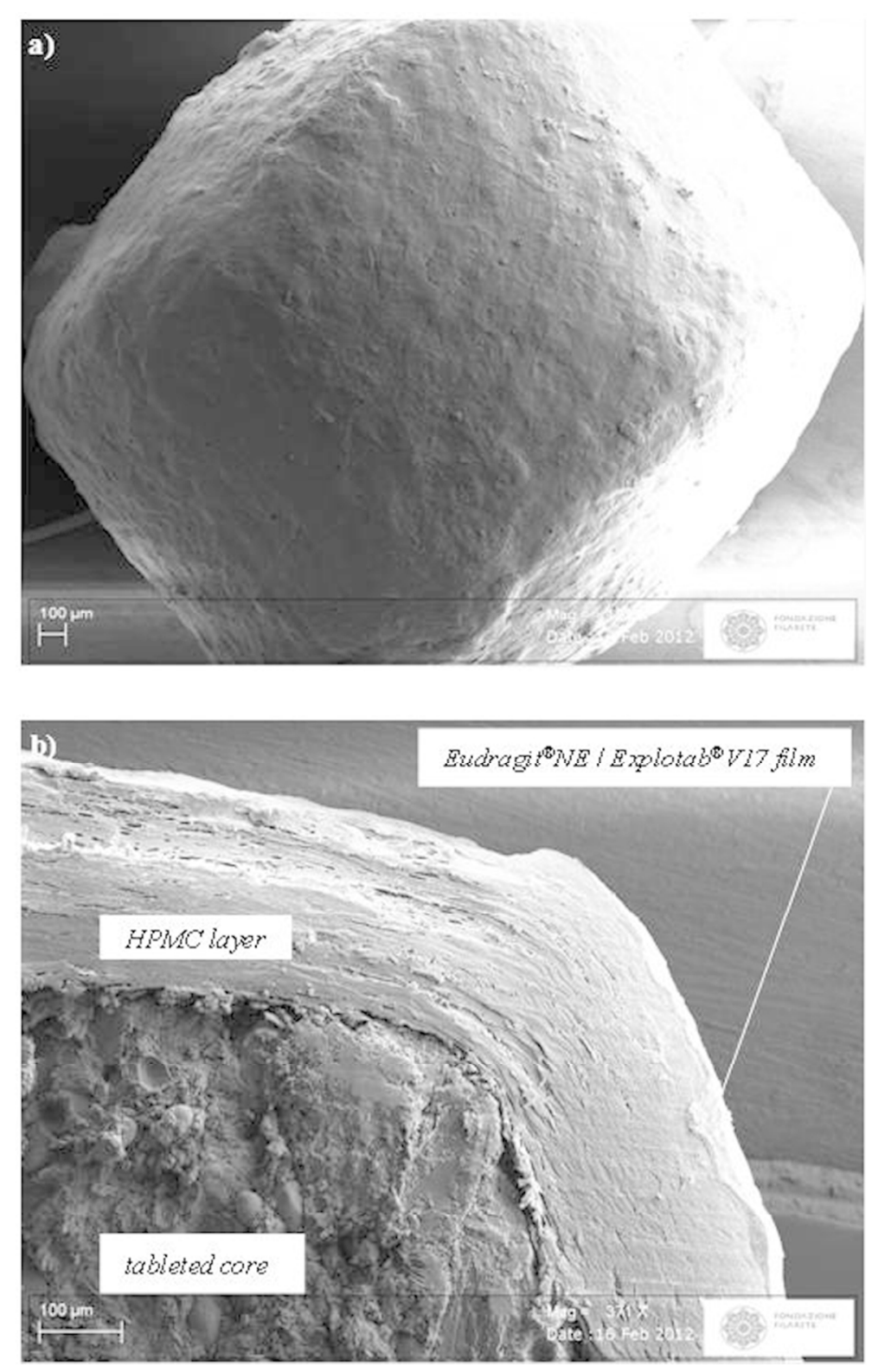

Figure 1. SEM photomicrographs of (a) mHENex20 with outer film of $10 \mu \mathrm{m}$ (magnification $122 \mathrm{x}$ ) and (b) cross section of the same formulation (magnification $371 \mathrm{x}$ ). $80 \times 125 \mathrm{~mm}(300 \times 300 \mathrm{DPI})$ 


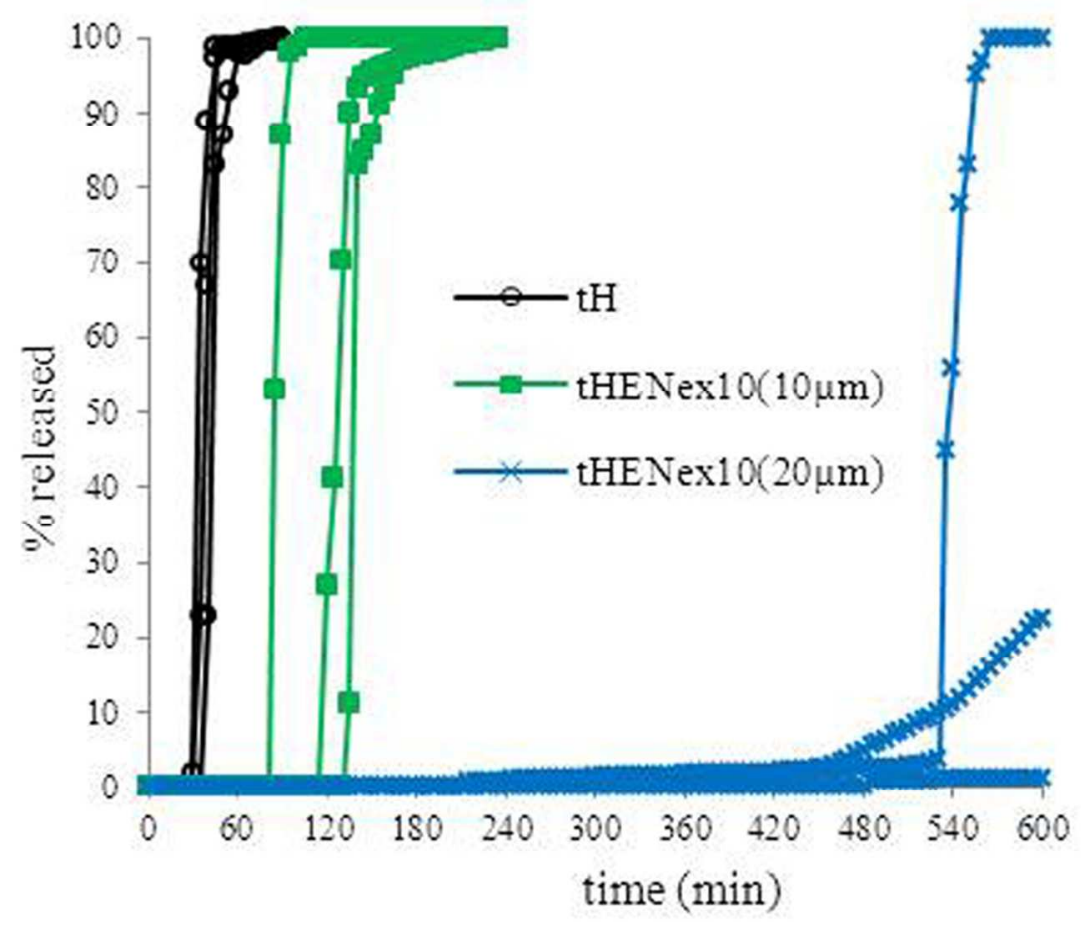

Figure 2. Individual release profiles of paracetamol from tH and tHENex10 with outer film of increasing thicknesses.

$80 \times 56 \mathrm{~mm}(300 \times 300 \mathrm{DPI})$ 


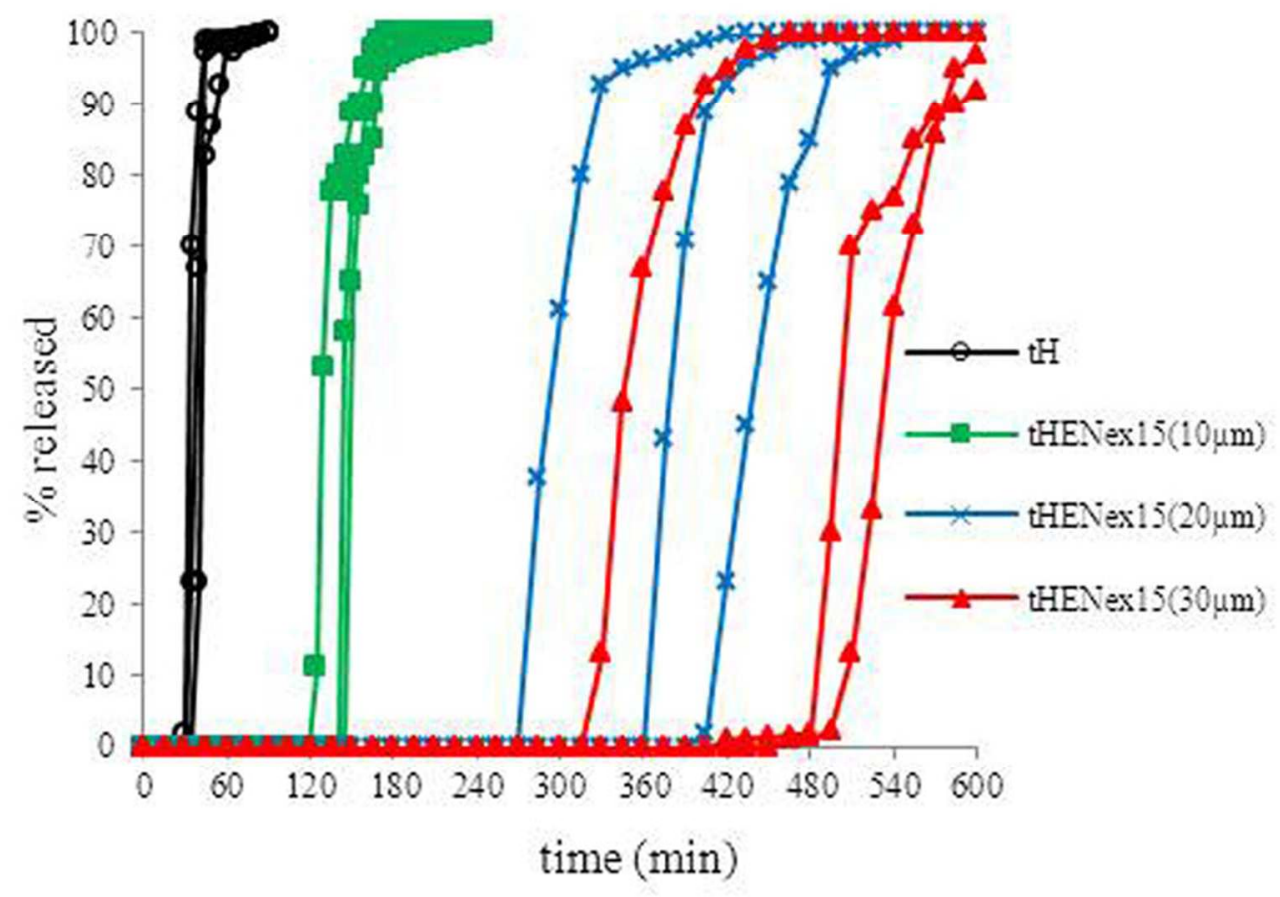

Figure 3. Individual release profiles of paracetamol from th and tHENex15 with outer film of increasing thicknesses.

$80 \times 56 \mathrm{~mm}(300 \times 300$ DPI $)$ 


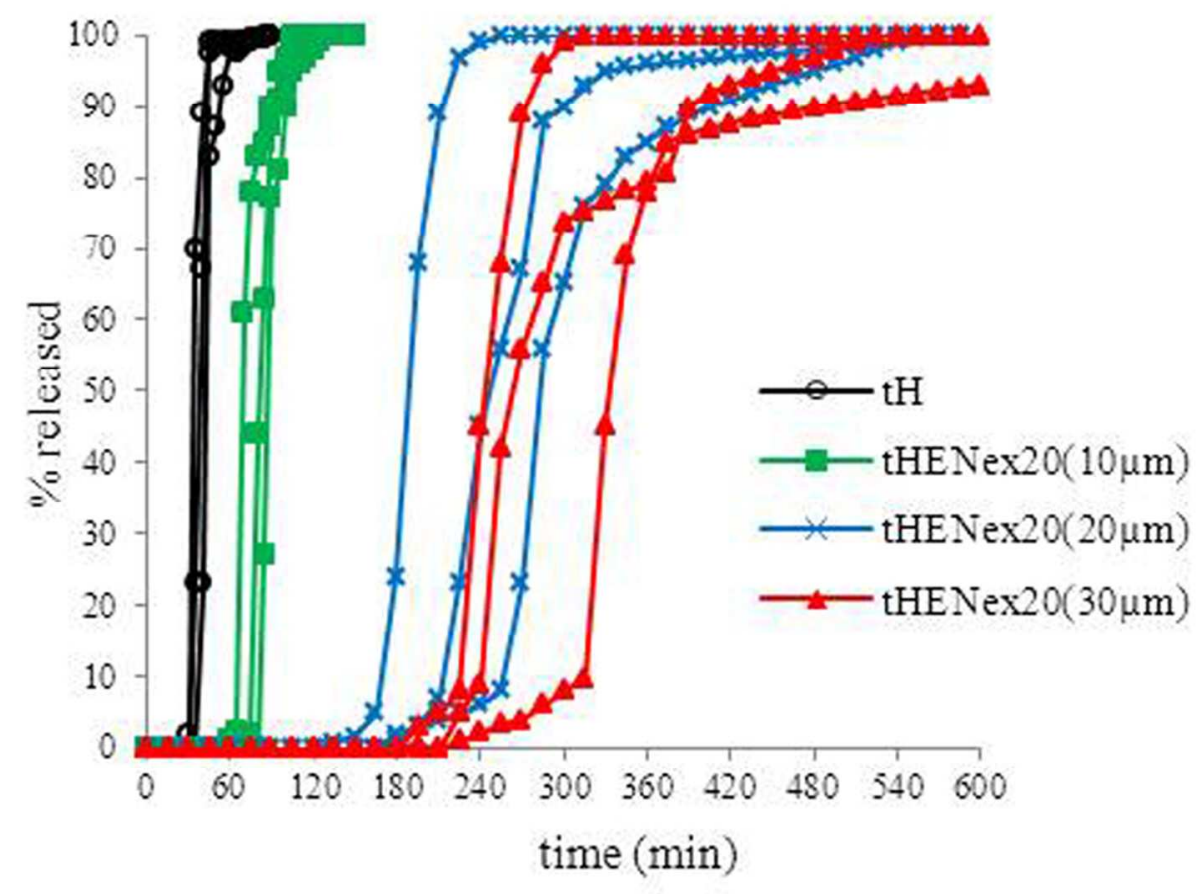

Figure 4. Individual release profiles of paracetamol from tH and tHENex20 with outer film of increasing thicknesses.

$80 \times 56 \mathrm{~mm}(300 \times 300 \mathrm{DPI})$ 


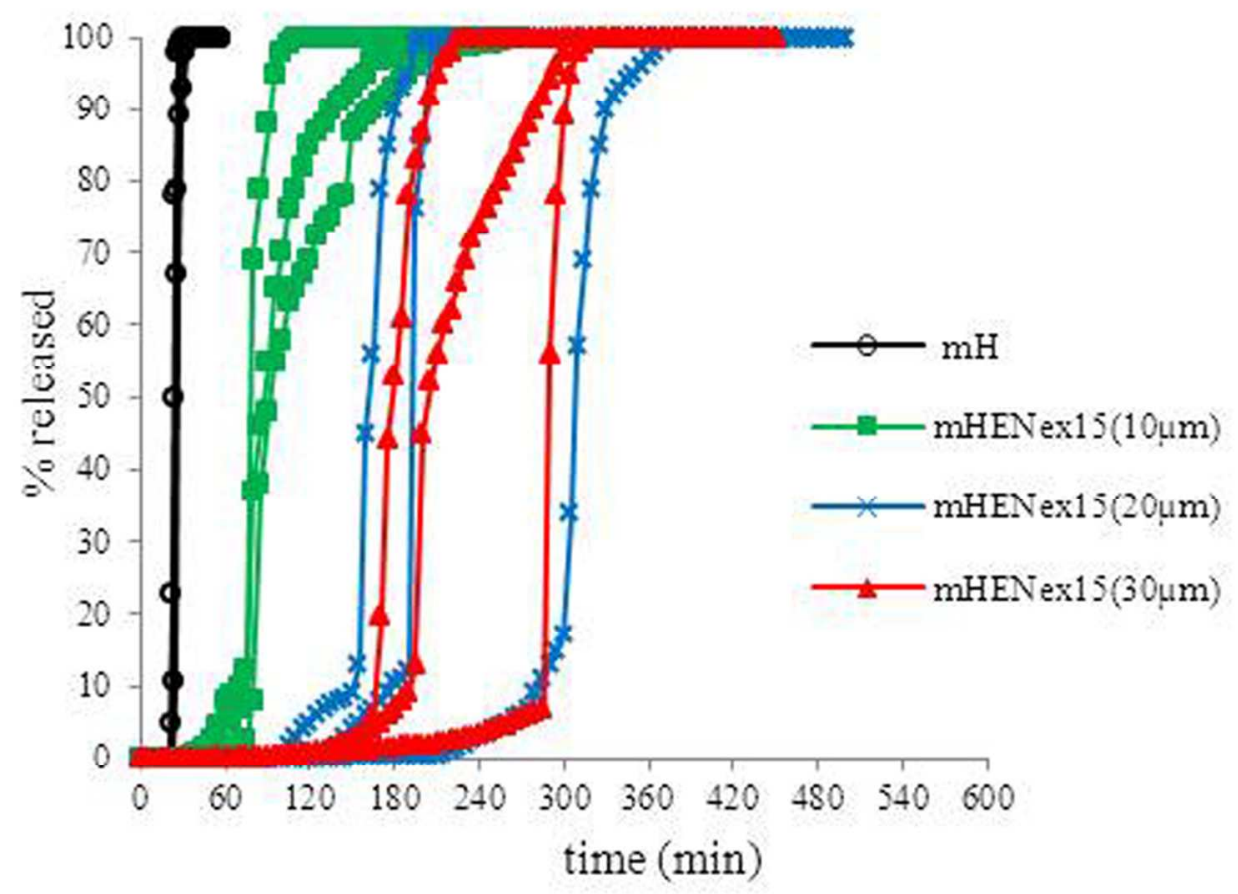

Figure 5. Individual release profiles of paracetamol from $\mathrm{mH}$ and $\mathrm{mHENex} 15$ with outer film of increasing thicknesses.

$80 \times 56 \mathrm{~mm}(300 \times 300 \mathrm{DPI})$ 


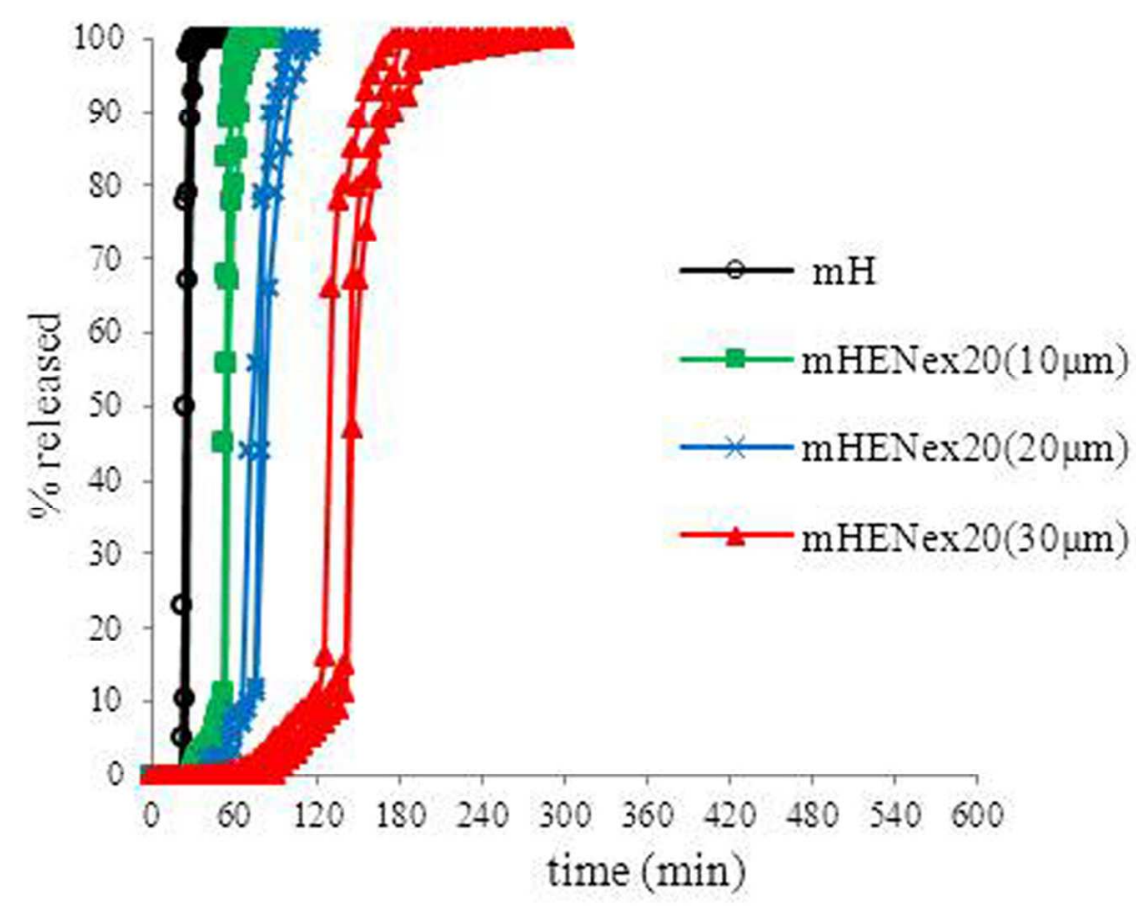

Figure 6. Individual release profiles of paracetamol from $\mathrm{mH}$ and $\mathrm{mHENex} 20$ with outer film of increasing thicknesses.

$80 \times 56 \mathrm{~mm}$ (300 x 300 DPI) 
a)
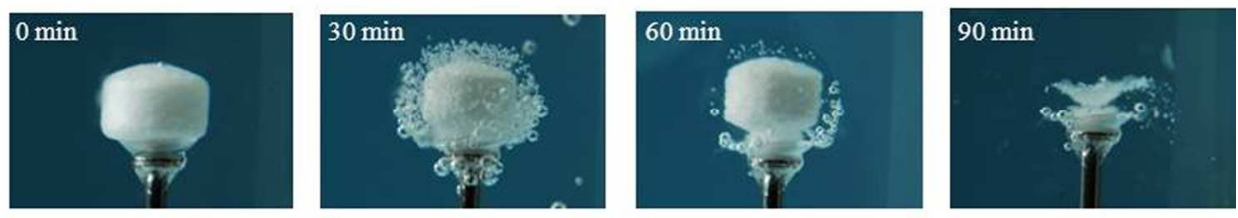

b)
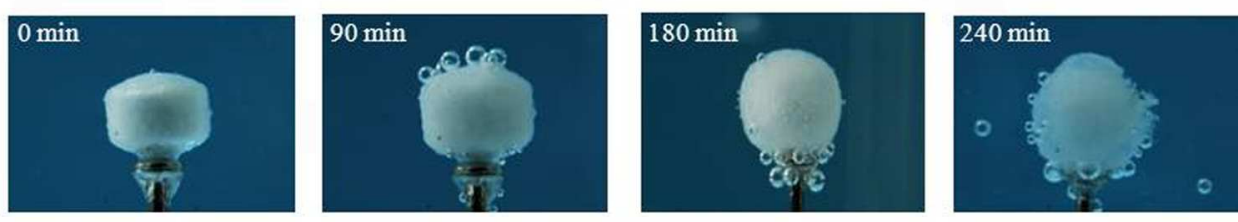

c)
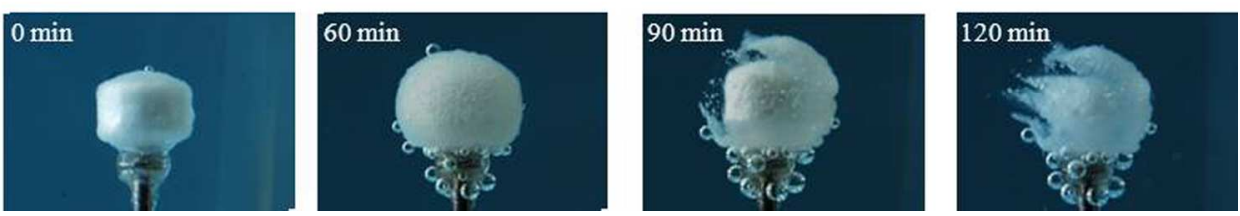

Figure 7. Photographs of (a) $\mathrm{mH}$, (b) mHENex15 and (c) mHENex20 with outer films of $30 \mu \mathrm{m}$ immersed in phosphate buffer $\mathrm{pH} 6.8$ at successive time points. $140 \times 76 \mathrm{~mm}(300 \times 300$ DPI) 


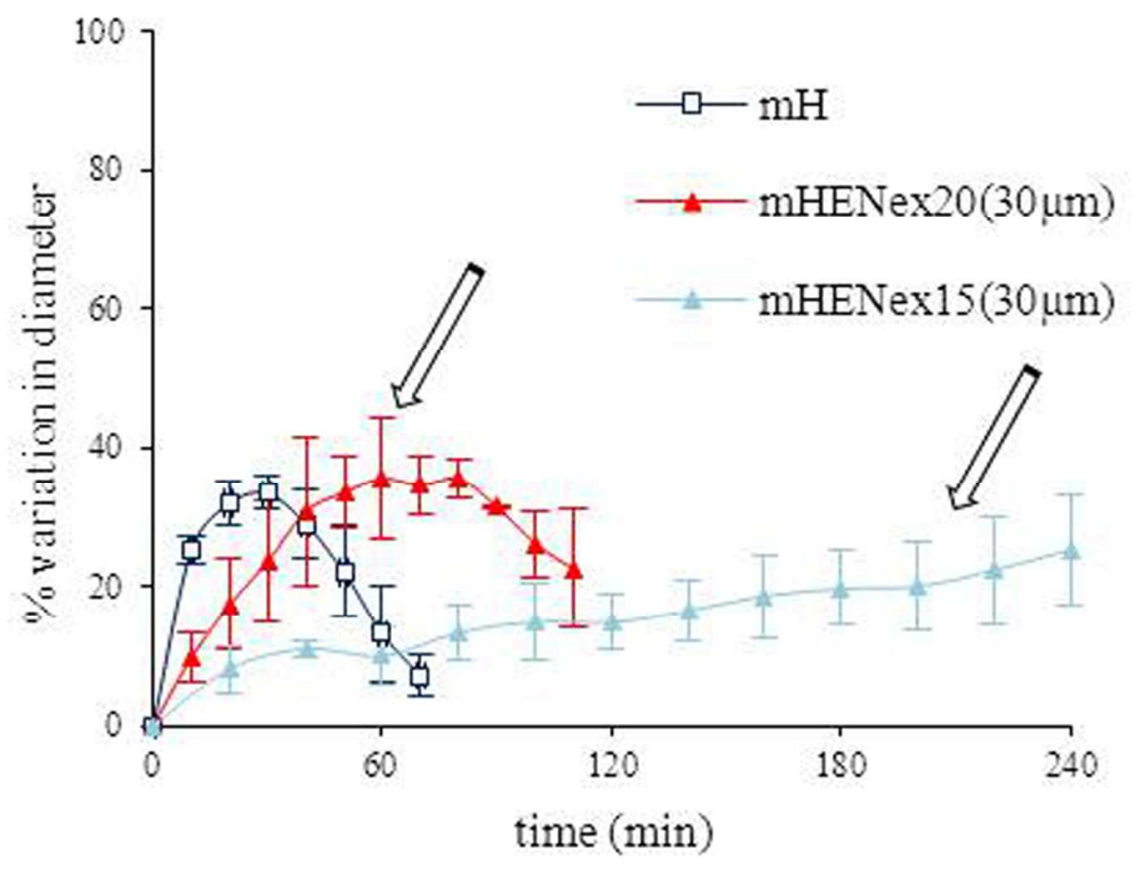

Figure 8. Mean \% variation in diameter vs. time curves of $\mathrm{mH}$ and mHENex15 as well as mHENex20 with outer films of $30 \mu \mathrm{m}$ immersed in phosphate buffer $\mathrm{pH}$ 6.8. Arrows and vertical bars indicate time of outer film break-up and standard deviation, respectively.

$80 \times 56 \mathrm{~mm}(300 \times 300 \mathrm{DPI})$ 

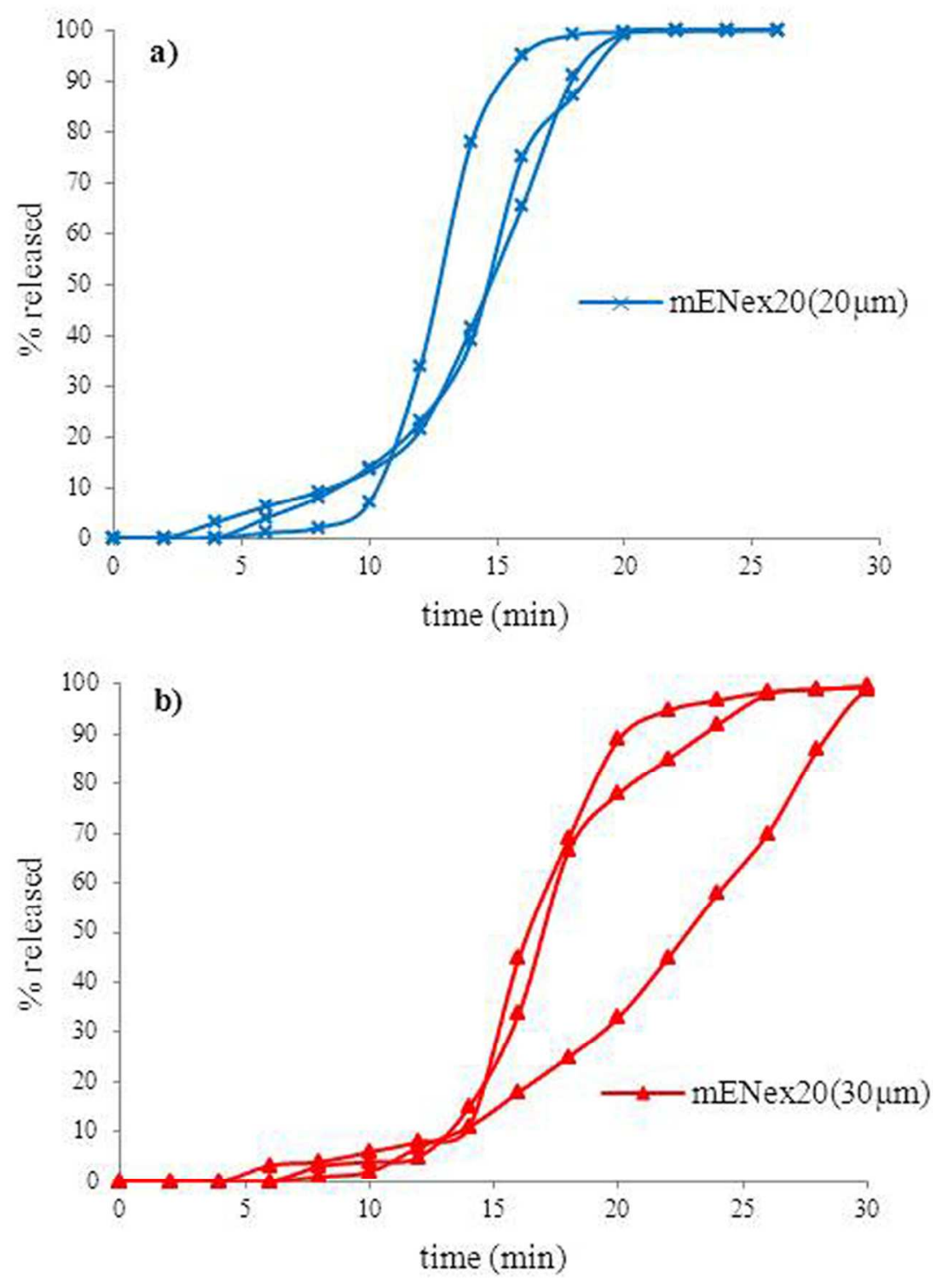

Figure 9. Individual release profiles of (a) mENex20 with outer film of $20 \mu \mathrm{m}$ and (b) mENex20 with outer film of $30 \mu \mathrm{m}$. $80 \times 112 \mathrm{~mm}(300 \times 300$ DPI $)$ 


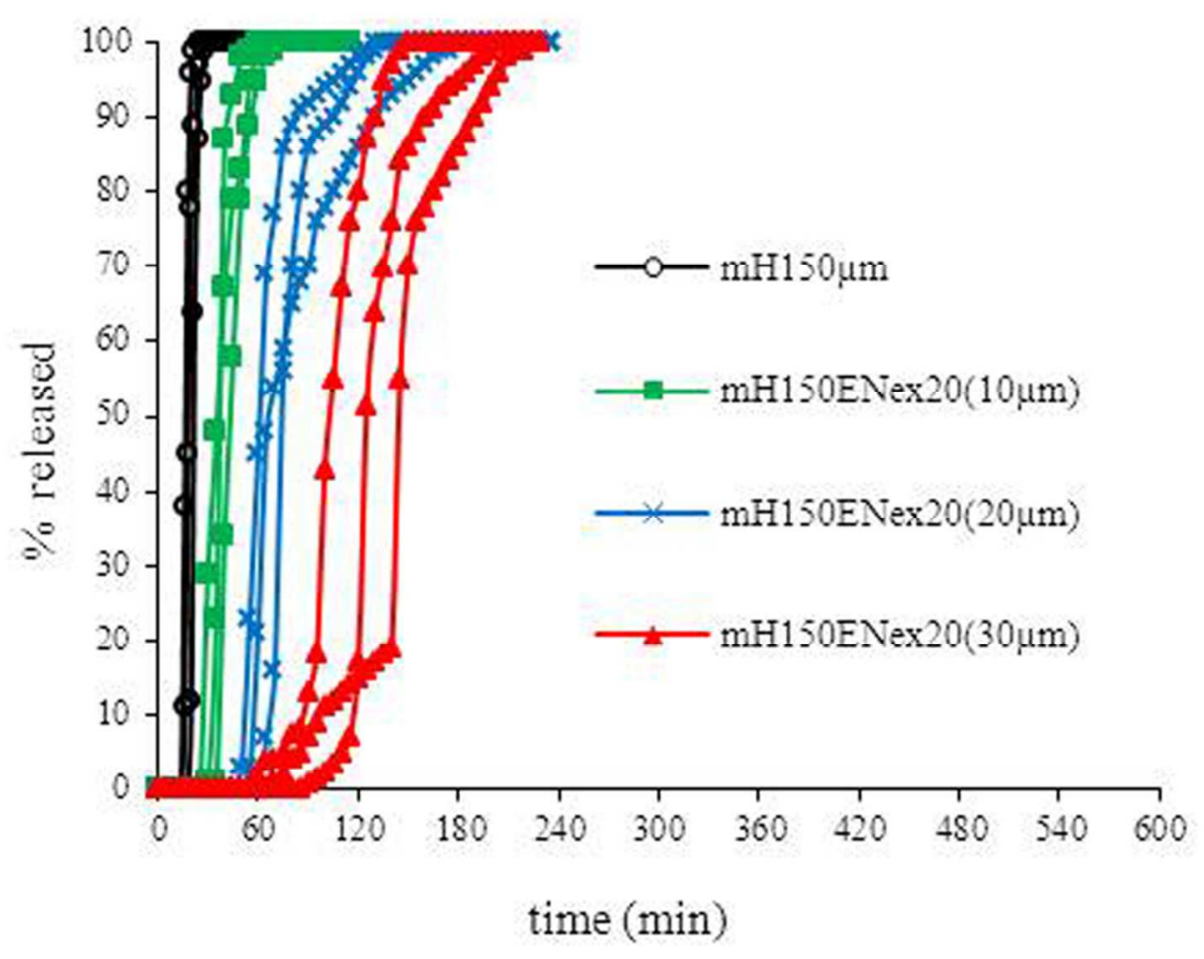

Figure 10. Individual release profiles of paracetamol from $\mathrm{mH}$ and $\mathrm{mH} 150 \mathrm{ENex} 20$ with outer film of increasing thicknesses. $80 \times 69 \mathrm{~mm}(300 \times 300$ DPI $)$ 


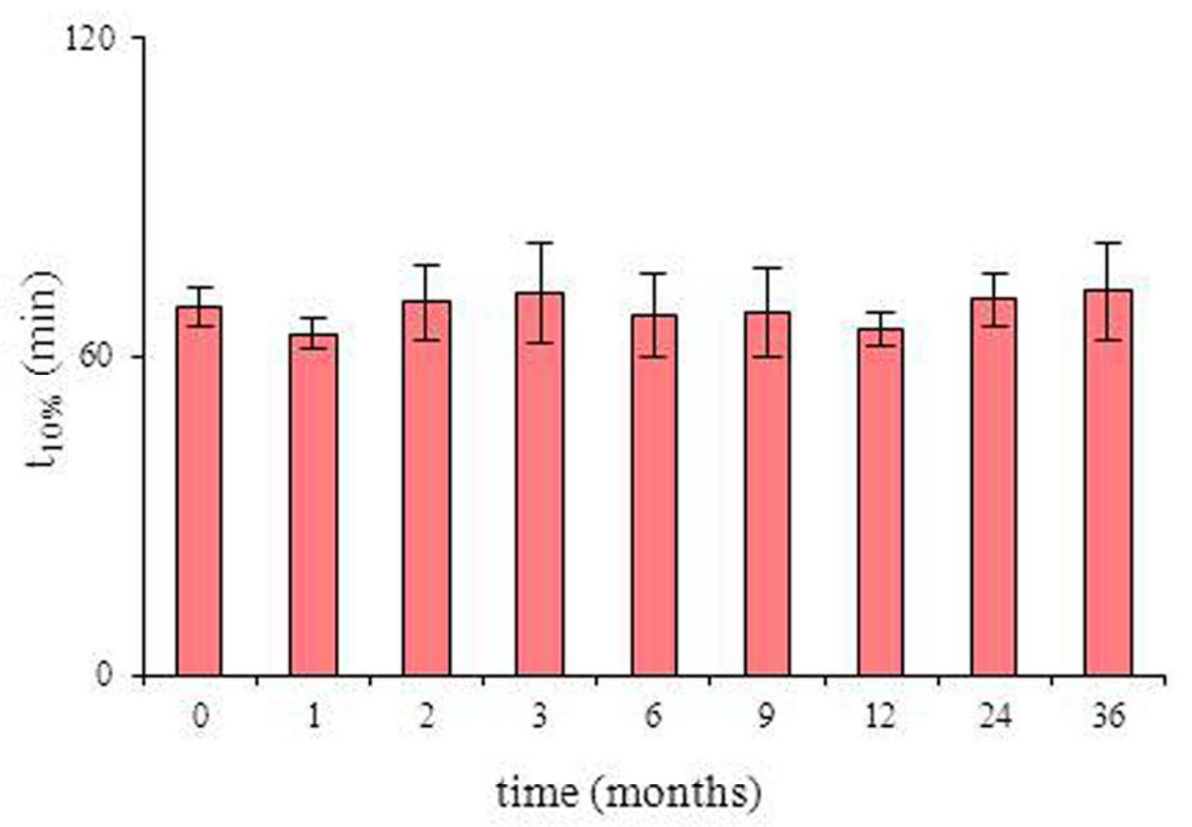

Figure $11 . t_{10 \%}$ of mHENex20 with outer film of $20 \mu \mathrm{m}$ at successive time points during 3 years of storage under ambient conditions ( $n=3$, vertical bars indicate S.D.).

$79 \times 58 \mathrm{~mm}(300 \times 300 \mathrm{DPI})$ 


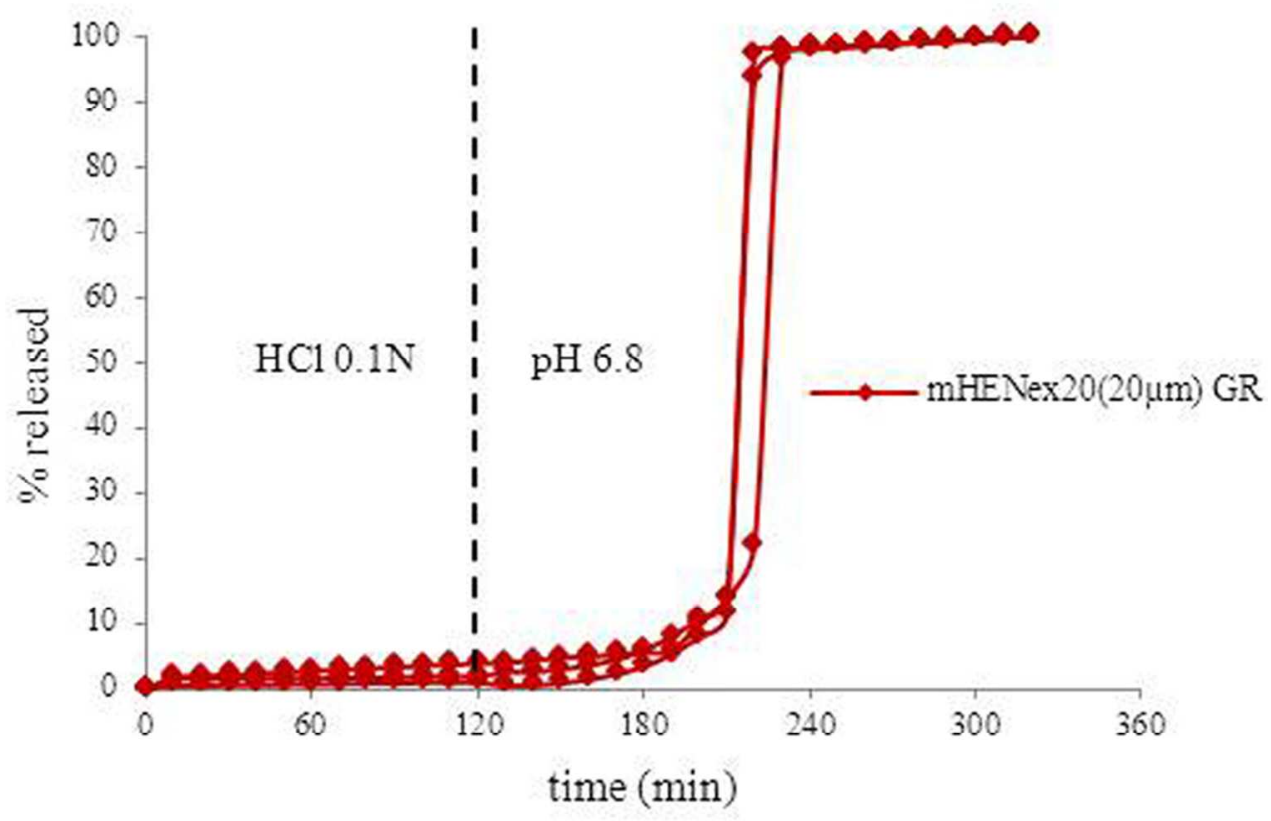

Figure 12. Individual release profiles of paracetamol from gastroresistant mHENex20 with Eudragit ${ }^{\circledR}$ $\mathrm{NE} /$ Explotab $^{\circledR} \mathrm{V} 17$ film of $20 \mu \mathrm{m}$.

$84 \times 56 \mathrm{~mm}$ (300 x 300 DPI) 